\title{
Small Dysplastic Oral Leucoplakia in a Smoking Woman: a Case Report
}

\author{
Caique Mariano Pedrosoํ, Gustavo Keller Schemberger², João Lucas Dziadzio², Letícia Caroline \\ Condolo $^{2}$, Priscila de Camargo Smolarek ${ }^{2}$
}

${ }^{1}$ Department of Oral Diagnosis, Piracicaba Dental School, University of Campinas (UNICAMP), Sao Paulo, Brazil.

${ }^{2}$ Department of Dentistry, State University of Ponta Grossa, Ponta Grossa, Brazil.

\author{
Corresponding Author: \\ Caique Mariano Pedroso \\ Department of Oral Diagnosis, Piracicaba Dental School \\ University of Campinas (UNICAMP) \\ 901 Av. Limeira, Post Code: 13414-903, Areião, Piracicaba, SP \\ Brazil \\ Phone: +5542991154613 \\ E-mail: caiquemp@yahoo.com.br
}

\begin{abstract}
Background: Oral leucoplakia is clinical term used to describe white plaques, and that is part of the group of oral potentially malignant disorders. Leucoplakia may show epithelial dysplasia, mainly in harder smoking patient. This case report discusses a small leucoplakia with dysplasia on the tongue's lateral border in a woman, diagnosed early after a routine clinical consultation. Methods: A 57-year-old female patient consulted to the Oral Diagnosis and Surgery Service of the State University of Ponta Grossa, Brazil. First, the patient was referred for the extraction of her lower incisors due to periodontal disease. During clinical examination, was identified a sessile white plaque, of small size, and located on the tongue's left lateral border. Thus, the lesion's diagnostic hypothesis was oral leucoplakia due to patient be chronic smoker for 40 years. The incisional biopsy was performed, with the epithelial tissue and part of the connective tissue removed.

Results: The histopathological examination revealed a stratified and keratinized pavement epithelium, with cellular atypia, and presence of hyperchromatism and nuclear pleomorphism. However, the alterations were restricted to the epithelium's basal, characterizing a mild dysplasia. The proposed treatment was surgical removal of the lesion, and the patient was also instructed to quit smoking, as well as she continues to follow-up.

Conclusions: The presented case emphasizes the importance of early diagnosis and the orientation of risk factors to smoking patients, even in small lesions that can clinically appear harmless.
\end{abstract}

Keywords: diagnosis; leucoplakia; smoking; risk factors.

Accepted for publication: 25 February 2021

To cite this article:

Pedroso CM, Schemberger GK, Dziadzio JL, Condolo LC, de Camargo Smolarek P.

Small Dysplastic Oral Leucoplakia in a Smoking Woman: a Case Report

J Oral Maxillofac Res 2021;12(1):e5

URL: http://www.ejomr.org/JOMR/archives/2021/1/e5/v12n1e5.pdf

doi: $10.5037 /$ jomr.2021.12105 


\section{INTRODUCTION}

Oral squamous cell carcinoma (OSCC) is the most frequent malignant neoplasm in the head and neck region [1]. This tumour is frequently the result of oral potentially malignant disorders (OPMDs), which are capable of transforming their tissue architecture. During cell division, OPMDs can undergo mutations and assume malignant tumour features. However, OPMDs may remain stable for long periods or never undergo malignant transformations [2] .

Among the oral lesions that present malignant transformation potentiality are leucoplakia, erythroplakia, erythroleukoplakia, and actinic keratosis [3] . Most of the agents associated with oral cancer development are also involved in the aetiology of OPMDs, such as chronic exposure to ultraviolet radiation, alcohol consumption, tobacco use (smoking), nutritional deficiency, and genetic inheritance [2].

Oral leucoplakia (OL) is a disorder of the white lesion group, which is diagnosed by the exclusion method. Additionally, OL is a clinical term used to describe white plaques of questionable risk, which does not fall under any other classification of this group [2]. The prevalence of OL is of 1 to $4 \%$ in the world population, being the OPMDs are more common, representing $85 \%$ of these lesions [3] This disorder's clinical aspect represents two types, classified as homogeneous or non-homogeneous OL [4]. Microscopically, it may present different histological degrees in its tissue architecture, ranging from simple hyperkeratosis to grades of oral epithelial dysplasia (OED), or to carcinoma itself [ $\underline{5}]$. The OED is an alteration whose severity is an indicator of malignancy; thus, progressing of a standard epithelium to OPMDs [] $]$.

The diagnostic criteria are essential since it decreases the risk of malignant transformation of the lesion. Examination of the oral cavity is the primary method of detection. However, the degree of dysplasia is determined not only by visual examination, and biopsy is mandatory [7]. In cases of OED in leucoplakia, treatment with the elimination of risk factors and longitudinal follow-up are essential to prevent the disorder's progress, favouring a good prognosis for patients [5]. In addition to dysplasia, other clinical predictors should be taken into account to assess the lesion's potential to malignant transformation [ [ $]$. In this context, this case report aims to discuss a clinical case of a smoking patient with small dysplastic oral leucoplakia, which was diagnosed early after a routine clinical consultation, observing the lesion's clinical and histopathological aspects.

\section{CASE DESCRIPTION AND RESULTS}

A 57-year-old female patient consulted to the Oral Diagnosis and Surgery Service of the State University of Ponta Grossa, Ponta Grossa, Brazil, in September 17, 2019. The patient was first referred for the extraction of her lower incisors due to periodontal disease. In the anamnesis, the patient reported no systemic changes and no use of medications. Women claimed to be a chronic smoker for 40 years, smoking approximately one cigarette pack daily. The physical examination was unremarkable. Oral examination identified a sessile white plaque, of small size (measuring about $2 \times 2 \mathrm{~mm}$ ), with a smooth surface and well-defined limits, firm palpation, painless, and located on the tongue's left lateral border (Figure 1). The patient was not aware of the lesion's presence at the moment of consultation, and, therefore, did not know how to inform the process of evolution. The lesion was adherent to the epithelium and did not stand out from the underlying oral mucosa. After the clinical findings, the lesion's diagnostic hypothesis was OL, following its classification in the homogeneous type.

The patient was oriented and recommended for incisional biopsy. Incisional biopsies are indicated in cases of OPMD's or suspected cases of malignant tumours, regardless of the size of the lesion. In this context, total removal of the lesion not being indicated through excisional biopsy. Therefore, remove the lesion complete, without knowledge about histopathology degree, might to compromise the injury margins, once the possibility of a malignant tumour might be present. First, anaesthesia was performed with lidocaine $2 \%$ and epinephrine 1 : 100,000 (Nova DFL; Taquara, Rio de Janeiro, Brazil), injected at four points around the lesion.

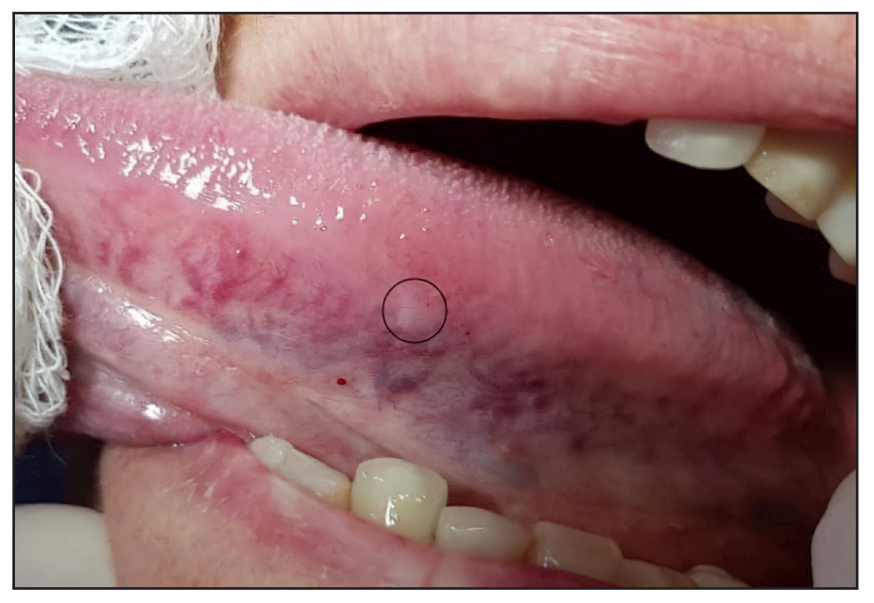

Figure 1. Clinical aspects of small oral leucoplakia located on the tongue's left lateral border. 
After the incision was made, the epithelial tissue and part of the connective tissue were removed. The oral tissue was sent for histopathological analysis, due to the patient being a chronic smoker, confirming or excluding OED's possibility.

Histopathological examination of a specimen stained with haematoxylin and eosin revealed a fragment of the oral mucosa coated with a stratified and keratinized pavement epithelium, with cellular atypia, and tissue architecture alteration (Figure 2). Among the cellular alterations, the report revealed the presence of hyperchromatism and nuclear pleomorphism (Figure 3). Additionally, an area compatible with the drop projection of epithelial tissue was observed (Figure 4). However, the alterations were restricted to the epithelium's basal and parabasal layers, characterizing a mild dysplasia. The connective tissue was normal, and there were no signs of inflammation. Thus, the diagnosis was compatible with the clinical hypothesis of OL, with mild epithelial dysplasia.

The patient was oriented regarding the risks and possible progression to malignant neoplasia. The proposed treatment was surgical removal of the lesion, and the patient was also instructed to quit smoking, which may be a factor in the lesion's development. In another consultation, in the same month, her teeth were extracted, and the patient was referred to periodontal monitoring. The patient was instructed to perform self-examination of the oral cavity. She attended the follow-up evaluations after three (in December 2019) and six months (in March 2020), with no recurrence of OL, and also reported to have discontinued the use of cigarettes. The patient will follow the monitoring for a minimum of two years, in order to control and not advance the lesion.

\section{DISCUSSION}

The present clinical case report describes an early diagnosis of a small dysplastic oral leucoplakia that presented classical clinical and histopathological features. These lesions present a particular risk of turning malignant $[\underline{8}]$.

Some clinical predictors of the malignancy of OL are advanced age, female gender, smoking, long duration of the lesion, diameter greater than two centimetres, non-homogeneous type, location on the tongue's lateral edge or the mouth's floor, and presence of OED $[\underline{5}, \underline{9}, \underline{10}]$. The chances of a malignant transformation occurring in a longer and larger lesion are higher than in a small lesion [3]. Although this case's patient did not know the evolution timeline,

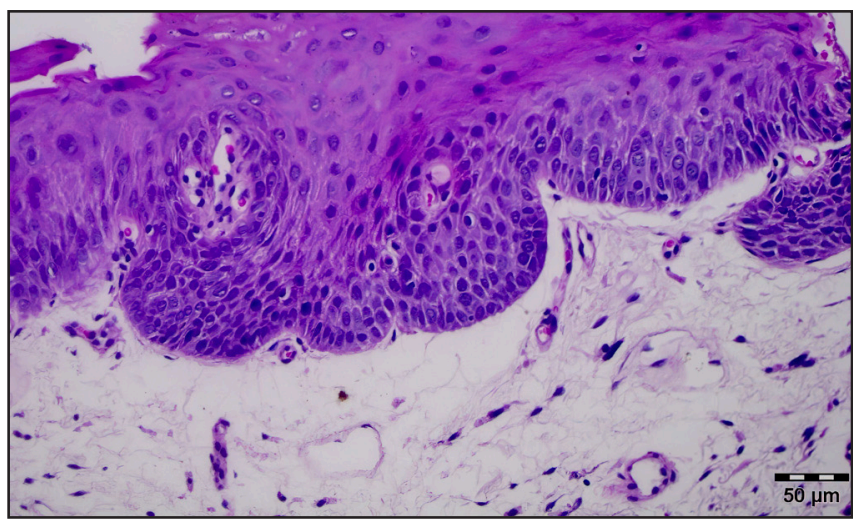

Figure 2. Features microscopic with a stratified and keratinized pavement epithelium, with cellular atypia, and tissue architecture alteration (haematoxylin and eosin stain, original magnification $\mathrm{x} 100)$.

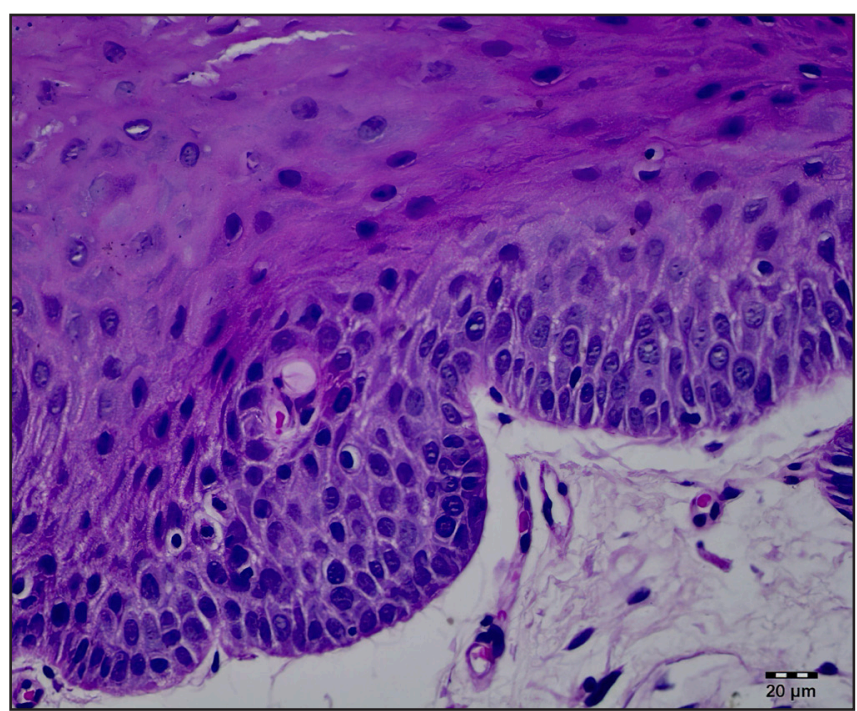

Figure 3. Alterations cytological with the presence of hyperchromatism and nuclear pleomorphism (haematoxylin and eosin stain, original magnification x200).

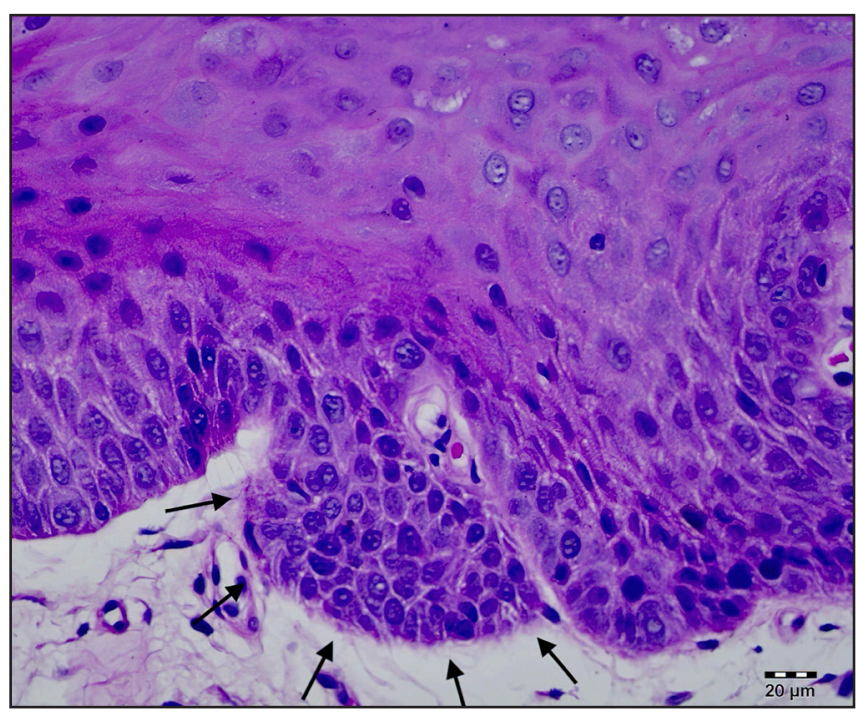

Figure 4. Alterations in architecture with the drop projection of epithelial tissue (black arrows) (haematoxylin and eosin stain, original magnification $\times 200$ ). 
and the lesion's small size at the time of diagnosis, the presence of OED was established. In this context, small lesions should not be underestimated and should be managed according to its histopathological features.

The lesion, diagnosed through its microscopic aspects, was compatible with the clinical hypothesis of OL. Alterations in the epithelium's tissue architecture were found, with atypical cells. OL without dysplasia has a worldwide prevalence of $4.1 \%$, whereas, when with OED, the prevalence is of $4.4 \%$ [ 3$]$. Among the microscopic findings, irregular stratification of the parabasal epithelium, hyperchromatism, and nuclear pleomorphism were observed, characteristics already described in the literature [11]. Different dysplasia degrees can occur histologically, being classified as mild, moderate, or severe [1]. This classification is essential for OL clinical management and to identify whether the lesion presents a low or high risk of malignancy.

In this case's histopathological analysis, mild epithelial dysplasia was accepted, considering the changes in the epithelium's parabasal layer. As variation in the epithelium's architecture, a drop-shaped epithelial projection was observed, a relevant histological characteristic of mild OED [11]. Iocca et al. [11] evaluated the clinical-pathological characteristics of OL who presented dysplasia, and $9.5 \%$ became malignant. Moreover, OL is the most prevalent OPMD. Compared to erythroplakia or erythroleukoplakia, this lesion presents a low percentage of malignant transformation [11]. In this case, the patient had habits that could enable the carcinogenic progression; however, the risk for malignant transformation proved to be low, which was confirmed by the clinical and pathological aspects of the lesion.

An OL is a white asymptomatic plaque that cannot be rubbed off and is not characterized clinically or pathologically by any other disease [12] This clinical description is compatible with our case. This lesion was also subclassified as a homogeneous type, established in the literature as a demarcated, uniform lesion, with a flat surface, which may exhibit shallow cracks [11]. The OLs are more common in male smokers over 50 years of age and are usually located in the tongue's lateral margin and the mouth's floor [13]. Our findings are in agreement with the literature; however, the patient in our study is female. This brief case report shows that, although the incidence of $\mathrm{OL}$ is higher among men, women are also subject to this disorder. Moreover, in its aetiology, OL has factors similar to those found in head and neck cancer [1]. The development of OL is common among $8.4 \%$ of patients who smoke tobacco [14].
Costa et al. [15] described that, in mild dysplasia cases in which risk factors are removed, such as quitting smoking, lesions tend not to reoccur after clinical conduct. In this case study, the patient was instructed to quit smoking, and informed about the lesion's potential to evolve to an OSCC. Longitudinal follow-ups are important for patients with chronic smoking profiles diagnosed with dysplastic OL, since continuing smoking can help progress to a malignant lesion, as reported by Welly et al. [16]. Additionally, Jayasooriya et al. [17] showed that the malignant transformation of OL occurred throughout a period of two and a half years, which corroborates the importance of continuous monitoring.

Cases of OL without OED should be guided by the removal of the risk factor with follow-ups every six months. For OL with dysplasia, surgical treatment is suggested, along with removing the causal factor, and follow-ups every three months [18]. In our case, surgery was performed conventionally, the lesion located in the lateral of the tongue removed entirely, and follow-ups were performed quarterly. The lesion's location and size guided the choice of therapy. In addition to conventional surgery, there are other therapeutic modalities for OL management, such as electrocautery, cryosurgery, laser ablation, or chemoprevention $[\underline{19}, 20]$. Van der Hem et al. [21] used the high-power laser in the treatment of $\mathrm{OL}$, and, in most of the treated patients, the lesion did not relapse. However, this result was not found by Brouns et al. [22], which showed the recurrence of OL after treatment. There is no evidence in the literature for which modality is the best for preventing malignant transformations of lesions [17]. In this context, regardless of the proposed management, quitting smoking is still the primary preventive measure, reducing the risk of malignant transformations after surgical treatment.

Clinical examination of all oral mucosa is essential, even if patients present other dental complaints. We emphasize that the patient's main complaint did not concern the lesion's presence, given she was not aware of the disease. Early diagnosis and the orientation of risk factors to smoking patients are part of the dentist's job in preventing oral cancer, favouring prognosis, and decreasing the possibilities of malignant transformation of OPMDs.

\section{CONCLUSIONS}

This case report shows that oral leucoplakia may occur in women who use tobacco (smoking), being the main risk factor. In addition, small lesion 
may also present with dysplasia. For this case, the examination of oral cavity was the best method for early diagnosis the oral leucoplakia, once the patients don't know about this disorder and sought care to treat periodontal disease. The follow-ups are essential for prevent the dysplastic oral leucoplakia transforms in oral squamous cell carcinoma. The patient continues to be followed-up at the university department for a minimum of two years. Therefore, guidelines such as stop smoking, and self-examination of the mouth should be passed on to patients with oral leucoplakia, in order to decrease the possibility of progression and turning malignant.

\section{ACKNOWLEDGMENTS AND DISCLOSURE STATEMENTS}

The authors report no conflicts of interest related to this study.

\section{REFERENCES}

1. Dionne KR, Warnakulasuriya S, Zain RB, Cheong SC. Potentially malignant disorders of the oral cavity: current practice and future directions in the clinic and laboratory. Int J Cancer. 2015 Feb 1;136(3):503-15. [Medline: 24482244] [doi: $10.1002 /$ ijc.28754]

2. Speight PM, Khurram SA, Kujan O. Oral potentially malignant disorders: risk of progression to malignancy. Oral Surg Oral Med Oral Pathol Oral Radiol. 2018 Jun;125(6):612-627. [Medline: 29396319] [doi: 10.1016/j.00oo.2017.12.011]

3. Pires FR, Barreto ME, Nunes JG, Carneiro NS, Azevedo AB, Dos Santos TC. Oral potentially malignant disorders: clinical-pathological study of 684 cases diagnosed in a Brazilian population. Med Oral Patol Oral Cir Bucal. 2020 Jan 1;25(1):e84-e88. [Medline: 31880285] [PMC free article: 6982984] [doi: 10.4317/medoral.23197]

4. Lodi G, Franchini R, Warnakulasuriya S, Varoni EM, Sardella A, Kerr AR, Carrassi A, MacDonald LC, Worthington HV. Interventions for treating oral leukoplakia to prevent oral cancer. Cochrane Database Syst Rev. 2016 Jul 29;7(7): CD001829. [Medline: 27471845] [PMC free article: 6457856] [doi: 10.1002/14651858.CD001829.pub4]

5. Ranganathan K, Kavitha L. Oral epithelial dysplasia: Classifications and clinical relevance in risk assessment of oral potentially malignant disorders. J Oral Maxillofac Pathol. 2019 Jan-Apr;23(1):19-27. [Medline: 31110412] [PMC free article: 6503768] [doi: 10.4103/jomfp.JOMFP 13 19]

6. raghunandan BN, Sanjai K, Kumaraswamy J, Papaiah L, Pandey B, Jyothi BM. Expression of human telomerase reverse transcriptase protein in oral epithelial dysplasia and oral squamous cell carcinoma: An immunohistochemical study. J Oral Maxillofac Pathol. 2016 Jan-Apr;20(1):96-101. [Medline: 27194869] [PMC free article: 4860945] [doi: 10.4103/0973-029X.180953]

7. Nagi R, Reddy-Kantharaj YB, Rakesh N, Janardhan-Reddy S, Sahu S. Efficacy of light based detection systems for early detection of oral cancer and oral potentially malignant disorders: Systematic review. Med Oral Patol Oral Cir Bucal. 2016 Jul 1;21(4):e447-55. [Medline: 26946209] [PMC free article: 4920458] [doi: 10.4317/medoral.21104]

8. El-Naggar AK, Chan JKC, Takata T, Grandis JR, Slootweg PJ. The fourth edition of the head and neck World Health Organization blue book: editors' perspectives. Hum Pathol. 2017 Aug;66:10-12. [Medline: 28583885] [doi: 10.1016/j.humpath.2017.05.014]

9. Irani S. Pre-Cancerous Lesions in the Oral and Maxillofacial Region: A Literature Review with Special Focus on Etiopathogenesis. Iran J Pathol. 2016 Fall;11(4):303-322. [Medline: 28855922] [PMC free article: 5563928]

10. van der Waal I. Oral potentially malignant disorders: is malignant transformation predictable and preventable? Med Oral Patol Oral Cir Bucal. 2014 Jul 1;19(4):e386-90. [Medline: 24905952] [PMC free article: 4119315] [doi: 10.4317/medoral.20205]

11. Iocca O, Sollecito TP, Alawi F, Weinstein GS, Newman JG, De Virgilio A, Di Maio P, Spriano G, Pardiñas López S, Shanti RM. Potentially malignant disorders of the oral cavity and oral dysplasia: A systematic review and metaanalysis of malignant transformation rate by subtype. Head Neck. 2020 Mar;42(3):539-555. [Medline: 31803979] [doi: 10.1002/hed.26006]

12. Agbor MA, Azodo CC, Tefouet TS. Smokeless tobacco use, tooth loss and oral health issues among adults in Cameroon. Afr Health Sci. 2013 Sep;13(3):785-90. [Medline: 24250322] [PMC free article: 3824433] [doi: 10.4314/ahs.v13i3.38]

13. Ganesh D, Sreenivasan P, Öhman J, Wallström M, Braz-Silva PH, Giglio D, Kjeller G, Hasséus B. Potentially Malignant Oral Disorders and Cancer Transformation. Anticancer Res. 2018 Jun;38(6):3223-3229. [Medline: 29848669] [doi: 10.21873/anticanres.12587]

14. Ramos RT, Paiva CR, de Oliveira Filgueiras AM, Silva-Junior GO, Heffer Cantisano M, de Carvalho Ferreira D, Ribeiro M. [Oral Leukoplakia: concepts and clinical repercussions]. Rev Bras Odontol. 2017 Jan-Mar; 74(1):52-55. Portuguese. [doi: $10.18363 /$ rbo.v74n1.p.51]

15. Herrera Costa F, Narana Ribeiro El Achkar V, Costa V, Paladini I, Kowalski LP, Rodarte Carvalho Y, Kaminagakura E. Different Expression of Aldehyde Dehydrogenases 1A1 and 2 in Oral Leukoplakia With Epithelial Dysplasia and in Oral Squamous Cell Carcinoma. Appl Immunohistochem Mol Morphol. 2019 Aug;27(7):537-542. [Medline: 29189260] [doi: 10.1097/PAI.0000000000000612] 
16. Weyll BMP, de Oliveira TFL, Carneiro Júnior B, Ramalho LMP. Oral leukoplakia: malignant transformation after four years of surgical excision. Rev Gaúch Odontol. 2012 Jul-Sep; 60(3):385-9. [URL: http://revodonto.bvsalud.org/pdf/rgo/v60n3/a17v60n3.pdf]

17. Jayasooriya PR, Dayaratne K, Dissanayake UB, Warnakulasuriya S. Malignant transformation of oral leukoplakia: a follow-up study. Clin Oral Investig. 2020 Dec;24(12):4563-4569. [Medline: 32436158] [doi: $10.1007 / \mathrm{s} 00784-020-03322-4]$

18. Liu W, Wang YF, Zhou HW, Shi P, Zhou ZT, Tang GY. Malignant transformation of oral leukoplakia: a retrospective cohort study of 218 Chinese patients. BMC Cancer. 2010 Dec 16;10:685. [Medline: 21159209] [PMC free article: $\underline{3009685}$ ] [doi: 10.1186/1471-2407-10-685]

19. Gondivkar SM, Gadbail AR, Choudhary MG, Vedpathak PR, Likhitkar MS. Photodynamic treatment outcomes of potentially-malignant lesions and malignancies of the head and neck region: A systematic review. J Investig Clin Dent. 2018 Feb;9(1). [Medline: 28480637] [doi: 10.1111/jicd.12270]

20. Lombardo EM, Gonçalves MR, Reis Só MV, Trevizani Martins MA, Carrard VC. [Oral Leukoplakia: Considerations about Treatment and Prognosis]. Rev Fac Odontol. Porto Alegre. 2018 Jan-Jun; 59(1):34-41. Portuguese. [doi: $10.22456 / 2177-0018.44770]$

21. van der Hem PS, Nauta JM, van der Wal JE, Roodenburg JL. The results of CO2 laser surgery in patients with oral leukoplakia: a 25 year follow up. Oral Oncol. 2005 Jan;41(1):31-7. [Medline: 15598583] [doi: 10.1016/j.oraloncology.2004.06.010]

22. Brouns ER, Baart JA, Karagozoglu KH, Aartman IH, Bloemena E, van der Waal I. Treatment results of CO2 laser vaporisation in a cohort of 35 patients with oral leukoplakia. Oral Dis. 2013 Mar;19(2):212-6. [Medline: 23323859] [doi: 10.1111/odi.12007]

\section{To cite this article:}

Pedroso CM, Schemberger GK, Dziadzio JL, Condolo LC, de Camargo Smolarek P.

Small Dysplastic Oral Leucoplakia in a Smoking Woman: a Case Report

J Oral Maxillofac Res 2021;12(1):e5

URL: http://www.ejomr.org/JOMR/archives/2021/1/e5/v12n1e5.pdf

doi: $10.5037 /$ jomr.2021.12105

Copyright (C Pedroso CM, Schemberger GK, Dziadzio JL, Condolo LC, de Camargo Smolarek P. Published in the JOURNAL OF ORAL \& MAXILLOFACIAL RESEARCH (http://www.ejomr.org), 31 March 2021.

This is an open-access article, first published in the JOURNAL OF ORAL \& MAXILLOFACIAL RESEARCH, distributed under the terms of the Creative Commons Attribution-Noncommercial-No Derivative Works 3.0 Unported License, which permits unrestricted non-commercial use, distribution, and reproduction in any medium, provided the original work and is properly cited. The copyright, license information and link to the original publication on (http://www.ejomr.org) must be included. 